\title{
DETERMINANTS OF QUALITY OF LIFE AMONG UPPER LIMB PROSTHESIS USERS PAKISTAN: A MULTICENTER STUDY
}

\author{
Faiza Sethi, Nazia Mumtaz*, Ghulam Saqulain** \\ Northwest General Hospital Hayatabad, Peshawar Pakistan, *Shifa Tameer-e-Millat University, Islamabad Pakistan, **Capital Hospital, Islamabad Pakistan
}

\begin{abstract}
Objective: To determine the quality of life among users of upper extremity prosthesis.

Study Design: Cross sectional study.

Place and Duration of Study: Day's Medical Engineering and Artificial Limbs Center Multan and Pakistan Institute of Prosthetic and Orthotic Sciences, Peshawar, Pakistan, from Jul to Dec 2018.

Methodology: A sample population of 276 users of upper extremity prosthesis was recruited employing convenience sampling including both genders aged 20-50 years. Demographic sheet, 36- Item Short Form Health Survey (SF-36) and Quick Disabilities of the Arm, Shoulder and Hand questionnaire (Quick-DASH) were used to collect data followed by analysis using SPSS-22.

Results: Mean score on Quick Disabilities of the Arm, Shoulder and Hand questionnaire was 49.2+25.4. The mean scores of 36- Item Short Form Health Survey revealed highest values in the domains of emotional wellbeing (55.8 \pm 17.7$)$ and energy/ fatigue $(54.0 \pm 14.3)$ while lowest values were noted in the role limitation due to emotional problems (38.9 \pm 33.5$)$ and General Health $(43.8 \pm 19.6)$ domains.

Conclusion: The study findings concluded that the overall quality of life of upper limb prosthetic user was low along with significant association of demographic features with SF-36 and Quick DASH.
\end{abstract}

Keywords: Amputation, Prostheses, Quality of life, Upper extremity.

How to Cite This Article: Sethi F, Mumtaz N, Saqulain G. Determinants of Quality of Life Among Upper Limb Prosthesis Users Pakistan: A Multicenter Study. Pak Armed Forces Med J 2021; 71(6): 2037-2040. ～Doi: https://doi.org/10.51253/pafmj.v6i6.4117

This is an Open Access article distributed under the terms of the Creative Commons Attribution License (https://creativecommons.org/licenses/by-nc/4.0/), which permits unrestricted use, distribution, and reproduction in any medium, provided the original work is properly cited.

\section{INTRODUCTION}

Amputation can be defined as the surgical or traumatic removal of a body extremity and rated as one of the most common acquired disabilities, ${ }^{1}$ with an incidence of 46.1 to 9600 per 10 (5) population around the world. ${ }^{2}$ The prevalence of upper limb amputation falls at 3\%.3 Amputation results in significant structural, physiological, and pscyho-social impact that can change the quality of life of these patients. ${ }^{1}$ In addition, it can be related with anxiety, depression and separation, changing the social roles and free time activities of an individual.

Amputation can result in the upper or lower limb deficiency and at different levels. Significance of hands and arms has been stressed by a number of authors, since loss of hand and arm result in loss of qualitatively different set of skill, compared to the loss occurring from lower limb amputation with different reasons like importance of hand and arm in actions of daily activities which are essential for living like holding items, gesturing as well as physical contact. ${ }^{4}$ Upper limb amputations can be classified into below elbow

Correspondence: Dr Ghulam Saqulain, House No. 171, Street 7-A, AECHS, Airport Society, Rawalpindi Pakistan

Received: 15 Apr 2020; revision received: 20 Oct 2020; accepted: 21 Oct 2020 including trans-carpal, forearm amputations and wrist disarticulations; and above elbow amputation include trans-humeral, forequarter amputations and shoulder disarticulations. ${ }^{5}$ Probable causes of upper limb amputation include trauma, vascular cause, tumors, infection and congenital anomalies. ${ }^{6}$ According to Ostlie et al. amputations of upper limb usually occur because of a specific "traumatic injury". ${ }^{7}$

Daily life activities including quality of life (Qol) have proved to be significantly compromised in amputees. In a study, Revicki et al, ${ }^{8}$ puts Qol as a wide range experiences in human being's life which are linked to his general feeling of wellbeing. It includes values related to a person's expectations of functioning defined by states, perceptions and individuals' experiences which are subjective in nature. According to Desmond and Gallagher though the concept of Qol in the field of amputation and prosthetics has been scarcely researched, however importance of its assessment has been acknowledged in client-centered evidence based practice. ${ }^{9}$ Consensus on the definition of Qol is still contentious with no gold standard for its measurement. However, assessment of benefits of an intervention for amputees can be seen as its effect on health-related Qol of an amputee. Using and adapting to a prosthetic limb 
with increasing physical activity, may lead to changes in an amputee's physical abilities and will likely influence self- reported Qol. ${ }^{10}$ Hence, this study is of utmost importance, keeping in view the significance of Qol in upper extremity amputees, a high prevalence rate and lack of local literature. Therefore, this research was done to determine the Qol among users of upper extremity prosthesis.

\section{METHODOLOGY}

This was a cross-sectional study. Sample population of either gender, aged 20-50 years was recruited using convenience sampling from Day's Medical Engineering and Artificial Limbs Center, Multan; and Pakistan Institute of Prosthetic \& Orthotic Sciences, Peshawar, Pakistan (PIPOS), from July to December 2018. Rao soft calculator was used to calculate sample size with a confidence level of $95 \%$ and margin of error of $5 \%$ taking a population size of 20 , (000 with $50 \%$ response distribution.

Inclusion Criteria: Upper limb amputees using prosthetic devices were included.

Exclusion Criteria: Bilateral amputees, Partial hand amputees; amputees with cognitive issues and any systemic illnesses and Orthosis users were excluded.

Following ethical approval of Institutional Research Board Isra University, (vide Registration No. 1609-M.Phil P \& O-002) dated 6th June 2018, and informed consent amputees were subjected to data collection using demographic sheet. This was followed by assessment of disability using Quick Disabilities of the Arm, Shoulder and Hand questionnaire (Quick-DASH) followed by quality of life (QOL) measurement using 36-Item Short Form Health Survey (SF-36) questionnaire. Data was collected from upper limb prosthetic users through questionnaires by certified Prosthetists and Orthotists.

Quick DASH is an 11-item questionnaire to assess the ability to perform upper extremity functions. This self-report measures scores functions on 5 point linkert scale. While SF-36 is a health related Qol questionnaire which has 36 items in 8 domains both physical and mental with a composite score ranging from 0-100. Mean score of normal general population is $50+10$ and a higher score indicates better Qol.

Following collection of data of upper limb prosthesis users by certified prosthetists and orthotists the data was analyzed by using Statistical Package for the social sciences (SPSS) version 22 and Ms Excel version 2016 software descriptive statistic were used including frequency, percentage, mean \pm SD. Pearson's correlation was noted for domains of SF-36 with DASH. The $p$-value of $\leq 0.05$ was taken as significant.

\section{RESULTS}

Study sample $(\mathrm{n}=276)$ comprised $230 \quad(83.3 \%)$ males and $46(16.7 \%)$ females and mean age was $29.5 \pm$ 12.5 years. Most of the participants were educated up to higher secondary school (HSC) level i.e. 182 (65.9\%), followed by $54(19.6 \%)$ who were above HSC. The most common single cause of amputation was accidents in 119 (43.1\%) causes. Most common amputation level was through radius (196, 71\%), followed by through humerus $(47,17 \%)$, wrist disarticulation amputation $(19,6.9 \%)$ and $12(4.3 \%)$ shoulder disarticulation amputation and $2(0.7 \%)$ were amputee of elbow disarticulation (Table-I).

Table-I: Frequency of demographic variables of quick DASH \& SF-36 (n=276).

\begin{tabular}{|c|c|c|}
\hline Variables & Categories & $\begin{array}{c}\text { Indifferent } \\
\text { Columns, } \mathrm{n}(\%) \\
\end{array}$ \\
\hline \multirow{4}{*}{ Age Groups } & 20-30 Years. & $161(58.3 \%)$ \\
\hline & 31-40 Years. & $60,(21.7 \%)$ \\
\hline & 41-50 Years. & $55(19.9 \%)$ \\
\hline & Male & $230(83.3 \%)$ \\
\hline \multirow{2}{*}{ Gender } & Female & $46(16.7 \%)$ \\
\hline & Married & $78(28.3 \%)$ \\
\hline \multirow{2}{*}{$\begin{array}{l}\text { Marital } \\
\text { Status }\end{array}$} & Unmarried & $198(71.7 \%)$ \\
\hline & $<\mathrm{HSC}$ & $182(65.9 \%)$ \\
\hline \multirow{3}{*}{$\begin{array}{l}\text { Education } \\
\text { level }\end{array}$} & $>\mathrm{HSC}$ & $54(19.6 \%)$ \\
\hline & Illiterate & $40(14.5 \%)$ \\
\hline & Businessman & $37(13.4 \%)$ \\
\hline \multirow{9}{*}{ Occupation } & Driver & $8(2.9 \%)$ \\
\hline & Govt. Servant & $36(13 \%)$ \\
\hline & House Wife & $15(5.4 \%)$ \\
\hline & Laborer & $43(15.6 \%)$ \\
\hline & Ex-Govt. Employee & $5(1.8 \%)$ \\
\hline & Self-Employed & $33(12 \%)$ \\
\hline & Student & $58(21 \%)$ \\
\hline & None & $41(14.9 \%)$ \\
\hline & \multicolumn{2}{|c|}{ Peripheral Vascular Disorder $1(0.4 \%)$} \\
\hline \multirow{4}{*}{ Causes } & Diabetes & $3,(1.1 \%)$ \\
\hline & Accident & $119(43.1 \%)$ \\
\hline & Other & $153,(55.4 \%)$ \\
\hline & Elbow Disarticulation & $2,(.7 \%)$ \\
\hline \multirow{4}{*}{$\begin{array}{l}\text { Amputation } \\
\text { Level }\end{array}$} & Shoulder Disarticulation & $12,(4.3 \%)$ \\
\hline & Through Humerus & $47,(17 \%)$ \\
\hline & Through Radius & $196,(71 \%)$ \\
\hline & Wrist Disarticulation & $19,(6.9 \%)$ \\
\hline
\end{tabular}

The mean Quick DASH score was $49.2 \pm 25.3$. As regards SF-36, the highest values were found in the domains of emotional wellbeing (55.8 \pm 17.6$)$ and energy/fatigue $(54 \pm 14.3)$, while the lowest values were noted for domains of role limitation due to emo- 
tional problems $(38.9 \pm 33.4)$ and General Health (43.8 \pm 19.5 ), Association of demographic variable with SF36 and quick DASH was noted for pain domain of SF36 which had significant correlation with occupation, The correlation of quick DASH with all eight domains of SF-36. Moderate negative correlations were found between Quick DASH and domains of physical functioning $(\mathrm{r}=-0.268, p<0.01)$, pain $(\mathrm{r}=-0.404, p<0.01)$ and general health $(\mathrm{r}=-0.401, p<0.01)$ and weak correlation with other domains of SF-36 shown in Table-II.

\begin{tabular}{|c|c|c|c|c|}
\hline Inven- & Domain & Mean \pm & Corr & ation \\
\hline tory & Domain & SD & r-value & $p$-value \\
\hline $\begin{array}{l}\text { Quick } \\
\text { DASH }\end{array}$ & Total & $49.2 \pm 25.4$ & & \\
\hline & $\begin{array}{c}\text { Physical } \\
\text { functioning }\end{array}$ & $47.7 \pm 29.7$ & $-0.268^{* *}$ & $<0.01$ \\
\hline & $\begin{array}{l}\text { Role physical } \\
\text { health }\end{array}$ & $46.9 \pm 40.2$ & $-0.166^{* *}$ & 0.006 \\
\hline 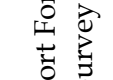 & $\begin{array}{c}\text { Role emotional } \\
\text { problems }\end{array}$ & $38.9 \pm 33.5$ & -0.087 & 0.152 \\
\hline क् & Energy/fatigue & $54 \pm 14.3$ & -0.095 & 0.117 \\
\hline 垔 & $\begin{array}{c}\text { Emotional well } \\
\text { being }\end{array}$ & $55.8 \pm 17.7$ & 0.009 & 0.887 \\
\hline dें & $\begin{array}{c}\text { Social } \\
\text { functioning }\end{array}$ & $48.5 \pm 25$ & $-0.190^{* *}$ & 0.002 \\
\hline & Pain & $48.4 \pm 32.9$ & $-0.404^{* *}$ & $<0.01$ \\
\hline & General health & $43.9 \pm 19.6$ & $-0.401^{* *}$ & $<0.01$ \\
\hline
\end{tabular}

Note: $r>0.50=$ strong correlation, $r=0.30=$ moderate correlation, and $r<0.20=$ weak correlation).

\section{DISCUSSION}

Prosthetic devices for the upper extremities are a technically difficult area since such prosthesis are expected to reproduce complex and delicate movements and hence such amputees may experience frustration and problems along with getting accustomed to the process of rehabilitation. However, recently development of prosthetic limbs using electronic technologies like myoelectric devices have taken place, the weight, lack of precision and speed in movements, are resulting in substantial glitches. ${ }^{11}$ However Michiro et al, in their study reported that Qol was much higher in prosthesis users compared to non-users and statistically significant differences were reported. ${ }^{12}$

In the current study high values of SF-36 mean domain scores were noted for emotional wellbeing $(55.8 \pm 17.6)$ and energy/fatigue $(54 \pm 14.3)$, followed by social functioning, pain and physical functioning indicating less disability and better Qol while the lowest values were noted for the domains including role limitation due to emotional problems $(38.9 \pm 33.4)$ and general health $(43.8 \pm 19.5)$ indicating more disability and lowered Qol. In addition, a mean score of Quick DASH of $49.2 \%$ was found indicative of low to moderate quality. Similarly in a study by Resnik et al, in upper limb amputees using body-powered devices mean score of Quick DASH was reported at 49.5.13

The present study showed a predominance of male, unmarried population with educational level of HSC and mean age of $29.5 \pm 12.5$ years. Results show association of demographic variable with SF-36 and Quick DASH (table1). For the pain domain of SF-36 significant correlation with age and occupation and education was noted. In addition, there was a significant relationship of age with 4 SF-36 domains including physical and social functioning, pain and general health. In addition, significant relationships were noted for domains of limitation of role because of physical function and emotional problems with cause of amputation; domain of emotional wellbeing with marital status, education and amputation level; and domain of general health with age, education, occupation, and level of amputation; and quick DASH with age, marital status, occupation, cause and level of amputation. Similarly, in other studies, statistically significant difference between Qol score and demographic variables has also been reported for age, ${ }^{14}$ gender, level of amputation, education level, ${ }^{15}$ etiology, and specially level of amputation affected the use of prosthesis. ${ }^{16}$ In this connection, Biddiss \& Chau, in study on upper limb amputees reported abandoning of prosthesis in $20 \%$ of cases with predisposing factors being limb absence bilaterally, origin of limb absence, gender and level of amputation being most important. ${ }^{16}$

Upper extremity functions significantly impact Qol both at physical and mental levels of an amputee.17 In the current study correlation of Quick DASH with all eight domains of SF-36 was noted with moderate negative correlations between the domains of physical functioning $(-0.268)$, pain $(-0.404)$ and general health ($0.401)$ and weak correlation with other domains of SF36. In addition, the correlation of Quick DASH with all the variables of SF-36 was significant $(p<0.05)$ except for domain of limitation of role because of emotional issues. While Nevena and Sanja reported statistically significant correlation of Quick DASH with role physical, role emotional, bodily pain and physical composite summary $(p<0.01) .{ }^{17}$ Also in another study by Atroshi et al, a positive correlation of Quick DASH scores with the SF-12 scores was reported with a 


\section{Upper Extremity Prosthesis}

stronger correlation with the physical than with the mental health component. ${ }^{18}$ In an Egyptian study by Mohammed and Shebl to assess the QOL in limb amputees revealed changes with significant difference of QoL with variables of gender, age, level of education and work type. ${ }^{15}$ Furthermore, scores were higher for males compared to females in the roles of physical functioning and emotional role. ${ }^{15}$

Better prosthetic systems may be helpful to improve patient acceptance, satisfaction \& QOL. So much so that rejection rate of $45 \%$ and $35 \%$ in children and $26 \%$ and $23 \%$ in adults for body-powered and electricpowered prosthesis was noted 19 also users in spite of having a myoelectric limb rely on intact limb 20, though the Qol is affected in amputees. ${ }^{17}$

In a review article, Cordella et al, pointed out the requirements of future prosthetic systems, which should be met for patient satisfaction. According to them the prosthesis should allow daily life task execution and include grasping and manipulation procedures; it should have tactile sensory system and control system which should help in daily activities like feeding, cleaning and dressing activities. ${ }^{21}$ It was reported in an Indian study that major design priorities of patients were comfort, functionality and durability. Furthermore, provision of subsidy, early provision and fitting facilitate long-term prosthetic use and improve rate of acceptance. ${ }^{22}$

\section{CONCLUSION}

The study findings concluded that the overall quality of life of upper limb prosthetic users was low along with significant association of demographic features with SF-36 and Quick DASH. Pain was associated with age and occupation; age with physical and social functioning, pain and general health; limitation of role because of physical function with cause of amputation; emotional wellbeing with marital status, education and amputation level; general health with age, education, occupation, and level of amputation; and quick DASH with age, marital status, occupation, cause and level of amputation.

\section{Conflict of Interest: None.}

\section{Authors' Contribution}

FS: Data collection, analysis \& Interpretation, NM: Conception of work \& critical revision, GS: Manuscript writing and literature review.

\section{REFERENCES}

1. Rybarczyk B, Edwards R, Behel J. Diversity in adjustment to a leg amputation: case illustrations of common themes. Disabil Rehabil 2004; 26(14-15): 944-953.
2. Moxey PW, Gogalniceanu P, Hinchliffe RJ, Loftus IM, Jones KJ, Thompson MM, et al. Lower extremity amputations-a review of global variability in incidence. Diabet Med 2011; 28(10): 1144-1153.

3. Pomares G, Coudane H, Dap F, Dautel G. Epidemiology of traumatic upper limb amputations. Orthop Traumatol Surg Res 2018; 104(2): 273-276.

4. Rybarczyk B, Behel J, Limb Loss and Body Image. In: Gallagher P., Desmond D, MacLachlan M, ed. Psychoprosthetics. London: Springer 2008; 1(1): pp 23-31.

5. Fahrenkopf MP, Adams NS, Kelpin JP, Do VH. Hand Ampu-tations. Eplast 2018; 18(1): ic21.

6. Maduri P, Akhondi H. Upper Limb Amputation. In: StatPearls. Treasure Island (FL): Stat Pearls Publishing 2019; 1(1): p1-46.

7. Ostlie K, Magnus P, Skjeldal OH, Garfelt B. Mental health and satisfaction with life among upper limb amputees: a Norwegian population-based survey comparing adult acquired major upper limb amputees with a control group. Disabil Rehabil 2011; 33(17-18): 1594-1607.

8. Revicki DA, Osoba D, Fairclough D, Barofsky I, Berzon R, Leidy NK, et al. Recommendations on health-related quality of life research to support labeling and promotional claims in the United States. Qual Life Res 2000; 9(8): 887-900.

9. Desmond D, Gallagher P. Quality of Life in People with Lower-Limb Amputation. In: Preedy VR, Watson RR. (eds) Handbook of Disease Burdens and Quality of Life Measures, New York, Spring NY 2010; 1(1): pp 3785-3796.

10. Deans SA, McFadyen AK, Rowe PJ. Physical activity and quality of life: A study of a lower-limb amputee population. Prosthet Orthot Int 2008; 32(2): 186-200.

11. Pylatiuk C, Schulz S. Results of an internet survey of myoelectric prosthetic hand users. Prosthet Orthot Int 2007; 31(1): 362-370.

12. Michiro Y, Kevin CC, Jennifer S, Melissa JS, Hirotaka T, Takashi N, et al. Cross-sectional international multicenter study on quality of life and reasons for abandonment of upper limb prostheses. Plast Reconstr Surg Glob Open 2019; 7(5): e2205.

13. Resnik L, Ekerholm S, Borgia M, Clark MA. A national study of Veterans with major upper limb amputation: survey methods, participants, and summary findings. PLoS One 2019; 14(3): e0213578.

14. Padovani MT, Martins MRI, Venâncio A, Forni JEN. Anxiety, depression and quality of life in individuals with phantom limb pain. Acta Ortopédica Brasileira 2015; 23(2): 107-110.

15. Mohammed SA, Shebl AM. Quality of life among egyptian patients with upper and lower limb amputation: sex differences. Adv Med 2014; 2014(1): 674323.

16. Biddiss E, Chau T. Upper-limb prosthetics: critical factors in de-vice abandonment. Am J Phys Med Rehabil 2007; 86(12): 977-987.

17. Karanović N, Stošić S. Upper extremity function and quality of life in patients with breast cancer related lymphedema. Vojno-sanit Pregl 2016; 73(9): 831-837.

18. Atroshi I, Gummesson C, Andersson B, Dahlgren E, Johansson A. The disabilities of the arm, shoulder and hand (DASH) outcome questionnaire: reliability and validity of the Swedish version evaluated in 176 patients. Acta Orthop Scand 2000; 71(6): 613-668.

19. Biddiss EA, Chau TT. Upper limb prosthesis use and aban-donment: A survey of the last 25 years. Prosthet Orthot Int 2007; 31(3): 236-257.

20. Chadwell A, Kenney L, Granat MH, Thies S, Head J, Galpin A, et al Upper limb activity in myoelectric prosthesis users is biased towards the intact limb and appears unrelated to goal-directed task performance. Sci Rep 2018; 8(1): 11084.

21. Cordella F, Ciancio AL, Sacchetti R, Davalli A, Cutti AG, Guglielmelli E, et al. Literature Review on Needs of Upper Limb Prosthesis Users. Front. Neurosci 2016; 10(1): 209.

22. Nagarajaa VH, Bergmanna JHM, Senb D, Thompsona MS. Examining the needs of affordable upper limb prosthetic users in India: A questionnaire-based survey. Technol and Disabil 2016; 28(3): 101-110. 